\title{
RAÍZES DA EFICIÊNCIA INDUSTRIAL NO PLANEJAMENTO DE CAMPUS
}

\section{PEREIRA, FÚLVIO TEIXEIRA DE BARROS}

Doutor em Arquitetura e Urbanismo (IAU/USP), professor da Universidade Federal de Campina Grande - UFCG, e-mail: fulvio.pereira@ufcg.edu.br

\begin{abstract}
RESUMO
Através de uma análise histórica, o artigo aborda como os preceitos da racionalização industrial emergiram, em início do século XX, na forma de planejar o campus nos Estados Unidos. Procura-se, neste estudo, expandir a compreensão do campus norte-americano para além de sua imagem tradicional, o conjunto universitário autônomo, suburbano e com amplas áreas verdes, e questionar a leitura da eficiência industrial como algo restrito às universidades federais brasileiras derivadas da reforma universitária de 1968 ou como um tema emergido no pós-Segunda Guerra Mundial, época de intensa expansão internacional do ensino superior. Para isso são analisados dois dos eventos introdutórios da modernização do ensino superior nos Estados Unidos: a publicação do estudo "Academic and industrial efficiency" (1910) e o projeto de Mies van der Rohe para o campus do Illinois Institute of Technology (1938-58). É constatado que tanto o estudo de Cooke quanto o projeto de Mies para o IIT punham em tensão o ideário tradicional de campus norte-americano, ao priorizarem a racionalização do espaço físico universitário.

PALAVRAS-CHAVE: campus universitário; universidades (arquitetura); projeto de arquitetura.
\end{abstract}

\section{RESUMEN}

A través de un análisis histórico, el articulo aborda cómo los preceptos de la racionalización industrial surgieron a principios del siglo XX en la forma de planificar el campus en los Estados Unidos. Se busca, en este estudio, expandir la comprensión del campus norteamericano más allá de su imagen tradicional, el conjunto universitario autónomo, suburbano y con amplias áreas verdes, y cuestionar la lectura de la eficiencia industrial como algo restringido a las universidades federales brasileñas derivadas de la reforma universitaria de 1968 o como un tema emergido en la post-Segunda Guerra Mundial, época de intensa expansión internacional de la enseñanza superior. Para eso analiza dos de los acontecimientos introductorios de la modernización de la enseñanza superior en los Estados Unidos: la publicación del estudio "Academic and Industrial Efficiency" (1910) y el proyecto de Mies van der Rohe en el campus del Illinois Institute of Technology (1938-58). Se constata que tanto el estudio de Cooke como el proyecto de Mies para el IIT ponían en tensión el ideario tradicional de campus norteamericano, al priorizar la racionalización del espacio físico universitario.

PALABRAS CLAVES: campus universitario; universidades (arquitectura); proyecto de arquitectura.

\section{ABSTRACT}

Based on historical analysis this study deals with how the precepts of industrial rationalization emerged in the early twentieth century in the form of planning the campus in the United States. It seeks in this study to expand the understanding of the North American campus beyond its traditional image, the university complex marked by autonomous, suburban and wide green spaces, and to question the reading of industrial efficiency as something restricted to the Brazilian federal universities derived from the university reform of 1968 or as a theme emerged in the post-World War II era of international expansion of higher education is questioned. For this, two of the introductory events in the modernization of higher education in the United States are analyzed: the publication of the study "Academic and Industrial Efficiency" (1910) and the Mies van der Rohe project for the Illinois Institute of Technology (1938-58). It is verified that both Cooke's study and Mies' IIT project put the traditional campus principles in tension by prioritizing the rationalization of the university's physical space.

KEYWORDS: campus; universities (architecture); architectural design.

\section{INTRODUÇÃO}

É reconhecido que os campi das universidades federais brasileiras resultantes da reforma universitária de 1968, ocorrida na ditadura militar e com assistência técnica norte-americana através dos convénios MEC/USAID, se basearam nos princípios da economia e da eficiência, os quais muito frequentemente continuam a guiar também as realizações mais recentes (PEREIRA, 2017).

Em contrapartida, os campi norte-americanos, apesar de servirem de exemplo para tais realizações, são geralmente identificados pela historiografia da arquitetura e do urbanismo como amplos espaços verdes apartados da cidade e voltados à sociabilização de seus usuários, sem equivalente sobrevalorização da eficiência de seu espaço físico. As obras de Paul Venable Turner, "Campus: an American planning tradition" (1984), e de Thomas Gaines, "The campus as a work of art" (1991), alinham-se a essa narrativa, ao se centrarem nas qualidades paisagísticas do campus. Porém tentativas de racionalizar a educação superior nos Estados Unidos já se revelavam no período de 1890 a 1930, com a presença de representantes da indústria 
e dos negócios no conselho de diretores das instituições de ensino. Antes mesmo da publicação de "Princípios da Administração Científica" (1911), principal obra de Frederick W. Taylor, o engenheiro mecânico Morris L. Cooke (1872-1960) realizou, sob o olhar de "um homem de negócios", uma análise do ensino superior norteamericano com base nos valores da administração industrial moderna, sob o título "Academic and industrial efficiency" (1910).

Além disso, nos anos 1940, o projeto de Mies van der Rohe para o campus do Illinois Institute of Technology - IIT (1938-58) foi uma solução paradigmática ao país, na qual o anseio de racionalização do ensino superior se formalizava pela primeira vez numa arquitetura igualmente racionalizada. Esse projeto foi amplamente divulgado, como na revista Architectural Forum, exaltado como "the first important group of U.S. educational buildings of modern design" (BUILDINGS..., 1942, p. 14). De fato, apesar da presença de princípios clássicos, como a simetria e a axialidade na definição de sua praça central, a arquitetura do IIT se destacava pela abstração plástica e espaços fluidos próprios à arquitetura moderna e pela racionalidade de seus edifícios derivada da eficiência industrial.

Por conseguinte, buscamos, neste estudo, expandir a compreensão do campus norte-americano para além de sua concepção unitária baseada na imagem tradicional do conjunto universitário autônomo, suburbano e com amplas áreas verdes. Buscamos, ainda, questionar a leitura da eficiência industrial como algo restrito às universidades federais brasileiras derivadas da reforma universitária de 1968 ou como um tema emergido no pós-Segunda Guerra Mundial, época de intensa expansão internacional do ensino superior.

Para isso investigamos, através de um estudo histórico, dois dos eventos introdutórios da modernização dos espaços físicos universitários nos Estados Unidos: a publicação do estudo "Academic and industrial efficiency" (1910), do engenheiro mecânico Morris L. Cooke (1872-1960), e o projeto de Mies van der Rohe para o campus do Illinois Institute of Technology (1938-58), o qual se tornou uma referência constante na historiografia sobre os espaços universitários. Através de ambos os objetos, buscamos identificar a emergência de preceitos da racionalização industrial na forma de planejar o campus norte-americano, mesmo que em realizações isoladas, e a precedência dessas discussões em relação à reforma universitária no Brasil, concretizada na ditadura militar.

\section{A RACIONALIZAÇÃO DO ENSINO SUPERIOR}

As origens do sistema de universidades norte-americanas são geralmente associadas ao ciclo de reformas iniciadas no final dos anos 1890 e culminadas nos anos 1920, quando a maioria dos colleges e universidades adotaram estruturas institucionais, rotinas de faculdades e sistemas financeiros próximos aos das modernas corporações (BARROW, 1992, p. 420). Ao contrário de uma inevitável resposta às demandas de modernização política e econômica, essa mudança foi induzida ativamente, como defende Barrow (1992, pp. 420-1), pela hegemonia financeira de uma nova elite corporativa e favorecida pela emergência do Estado central, quando uma agenda liberal era implantada. Pois os crescentes custos e a lentidão da maioria das instituições modernizarem seus currículos resultaram na queda de confiança das empresas e motivaram a oferta de investimentos privados para esse fim, realizados de forma seletiva e direta, para induzirem as reorganizações institucionais (Idem, p. 422).

Paralelamente também se deu a pressão pela regulação do desenvolvimento educacional e por maior intervenção estatal central (BARROW, 1992, p. 422). Em início dos anos 1900, surgiram duas importantes fundações educacionais: General Education Board, criada em 1903 pelo industrial John D. Rockefeller, e Carnegie Foundation, criada em 1902 pelo industrial Andrew Carnegie. Para além de seus fundadores, os membros dessas novas fundações educacionais emergiram como indivíduos que eram homens de negócios/educadores/experts técnicos ou alguma variação de tais perfis (Idem, p. 424). O comitê executivo da Carnegie Foundation, por exemplo, era, de 1906 até 1929, composto 80\% por diretores ou executivos de grandes corporações financeiras ou industriais (Ibidem, p. 424). Além disso, o autor ressalta que essas e outras instituições constituíram uma rede de planejamento político ancorado em corporações industriais e instituições financeiras.

Desde o final da Guerra Civil (1861-1865), as modernas universidades norte-americanas tinham como principal referência as universidades alemãs. E passavam a se diferenciar em forma e função dos anteriores colleges predominantes no país. Nessa direção, inicialmente não possuíam dormitórios, davam pouca importância à vida extracurricular dos estudantes e tinham edifícios com caráter utilitário e econômico. Superada, em pouco tempo, essa orientação inicial, as universidades norte-americanas passaram a unir os valores tradicionais dos colleges, em especial a vida comunitária, a novas características, como complexidade de estrutura, voltada a vários estudos especializados, localização geralmente urbana, com pouca diferenciação em relação à cidade, e grande quantidade de público. 
A renovação se estendeu também à arquitetura do campus a fim de representar a natureza da nova instituição. Foram utilizados com frequência princípios do City Beautiful, em evidência nos Estados Unidos e que uniam o planejamento ordenado ao anseio de uma monumentalidade simbólica, que era, por sua vez, uma solução oportuna para valorizar os crescentes investimentos particulares no ensino superior, em final do século XIX. Por outro lado, diante da maior complexidade assumida pelas instalações de ensino superior, que requeriam inúmeros e diversos edifícios, o planejamento do campus ganhava importância com a valorização do plano diretor, afora numerosos artigos sobre planejamento de colleges e universidades em revistas especializadas (TURNER, 1995, p. 186). Como resultado, a ideia de vila anteriormente associada ao campus deslocou-se, como percebido por Turner (Idem, p. 167), para a noção de cidade.

E essa não foi uma transformação linear e sem tensões. Como eram grandes as dimensões que as universidades passavam a assumir, surgiram críticas contra a impessoalidade de seu ensino. Tentativas, em início do século XX, de retomar a escala dos tradicionais colleges enquadravam-se nessa perspectiva. De forma aparentemente nostálgica, foram construídos edifícios segundo "quadrângulos" monásticos, que derivavam dos colleges medievais britânicos e concentravam numa pequena área os espaços de convívio acadêmico, afora isolá-los em relação ao espaço urbano. Essa solução estranha à tradição universitária norteamericana não foi duradoura e deu lugar ao retorno da concepção do campus a partir de edifícios isolados e coordenados por princípios de composição acadêmica, como a organização simétrica e axial, independentemente do estilo arquitetônico utilizado.

Nesse momento de reestruturação do ensino superior no país, o estudo publicado por Morris Llewellyn Cooke era derivado de uma encomenda da Carnegie Foundation dirigida a Frederick Taylor, com o fim que ele conduzisse um "estudo econômico sobre educação" para contribuir com uma "eficiente estandardização" das instituições de ensino superior norte-americanas (BARROW, 1992, p. 425). Para essa atividade, Taylor recomendou seu discípulo e amigo pessoal, Cooke.

Segundo Cooke (1910, p. 3), o objeto central do estudo era realizar uma estimativa de custos e resultados nas atividades de ensino e pesquisa. Por conseguinte, propôs a modernização do ensino superior baseada na "administração funcional" de Frederick Taylor, o que implicava na analogia da educação a um negócio, apesar das diferenciações entre ambas as atividades, como alertado no próprio prefácio de sua obra. Dentro desse enfoque, considerava que o problema da eficiência acadêmica deveria ser resolvido com o aumento da produtividade da força de trabalho e da utilização de edifícios e equipamentos. Visto que seu estudo era dedicado predominantemente à modernização da gestão dos colleges e universidades, as ideias sobre o espaço físico não eram extensas, se concentraram no capítulo "The Economical Use of Buildings", no qual Cooke se detinha em alcançar a máxima eficiência, como comum a uma organização industrial. Afinal, em seu entendimento: "If there is one think that stands out as an example of inefficiency, it is the degree of use to which college buildings are put" (Idem, p. 35). Para isso ele utilizava como unidade de referência o tempo médio de uso das salas ou edifícios por dia, a exemplo de sua insatisfação ao registrar que não existiam, na área de Física, salas de aulas ocupadas mais de quatro horas por dia.

Como solução o autor propunha que a administração de todos os edifícios deveria estar nas mãos de alguma autoridade central e ser operada com base em regras tão completas quanto pudessem ser estabelecidas (COOKE, p. 36). Essas deveriam ser aplicadas a todos os edifícios independentemente dos objetivos para os quais fossem usados. Nesse entendimento, a eficiência do espaço físico universitário seria gerada pelo compartilhamento das salas e edifícios por distintos departamentos, ao invés de seu uso por um único departamento. Para isso, além da gestão centralizada desses espaços, era necessário, como sugerido pelo autor (Idem, p. 37), que cada universidade estabelecesse padrões de tamanho e desenho das salas usadas para determinado fim. Uma sala de aula de Física para 20 alunos não deveria, por exemplo, se diferenciar de uma sala de aula de Matemática com a mesma capacidade.

Embora seu estudo não se detivesse em outros aspectos do espaço físico, como a organização do conjunto, estabelecia duas ideias que seriam usuais nas futuras realizações universitárias do país: quantificar a eficiência de utilização dos espaços físicos, através da unidade de medida "horas por dia", e propor o uso compartilhado dos espaços e/ou edifícios ao invés de destiná-los para departamentos específicos.

A julgar pela posterior presença de Cooke no Brasil, onde em 1942, durante o Estado Novo, ele se tornaria o chefe da missão de assistência técnica norte-americana ao governo brasileiro que visava promover o desenvolvimento econômico do país - conhecida como Missão Cooke -, suas ideias obtiveram considerável receptividade local. A importância dada à economia e à eficiência na reforma universitária de 1968, direta ou indiretamente se assemelha aos princípios defendidos por Cooke, embora, no caso particular de sua obra "Academic and industrial efficiency" (1910), ainda pouco se saiba sobre a recepção brasileira. 


\section{O EXEMPLO PARADIGMÁTICO DO IIT}

Se o livro de Cooke propunha premissas para a modernização do espaço físico universitário, o projeto de Mies para o IIT demonstrava a possibilidade de uma organização racional ao campus, quando ainda era, nos anos 1930, rara e cercada por controvérsias a utilização da arquitetura moderna nas universidades dos Estados Unidos. Em contrapartida, essa arquitetura já tinha uma progressiva aceitação em outros programas, afora o esforço para promovê-la, como o realizado pela revista Architectural Forum, que foi uma de suas principais defensoras (TURNER, 1984, p. 251).

O IIT caracterizava-se por sua linguagem fabril resultante da padronização e da seriação, que era então incomum aos campi norte-americanos. Sua solução repercutia a própria orientação tecnológica da instituição, criada em 1940 pela fusão do Armour Institute of Technology (fundado em 1893 e dedicado à engenharia, química, arquitetura e biblioteconomia) e do Lewis Institute (fundado em 1895 e dedicado às artes liberais e cursos de engenharia). Por outro lado, era favorecida pelo ambiente cultural de Chicago, considerada por Cohen (1994, p. 84), "[...] sans doute l'un des lieux où l'alliance entre industriels et architectes tant revendiquée par le Werkbund se dessine le plus nettement".

O campus do IIT situava-se numa área caótica, ocupada por favelas e próxima ao centro de Chicago, onde foram estabelecidos, desde 1901, os edifícios do anterior Armour Institute of Technology. Diante disso, seu projeto fez parte da reestruturação da área que, no entanto, levou à exclusão da população negra, com a eliminação de cerca de sessenta quilômetros quadrados de favelas pelo "Master Plan of Residential Land Use" de 1943 (COHEN, 1994, p. 84).

Não obstante as especificidades socioeconômicas locais, a solução encontrada por Mies foi indiferente à situação urbana e à história do lugar. Dentro do princípio da "tábula rasa", ele inicialmente propôs a eliminação das ruas preexistentes para transformar as quadras num vasto terreno único, sem a circulação de veículos em seu interior e com a possibilidade de posicionar livremente os edifícios. E as construções preexistentes da instituição não seriam preservadas. Graças a esses artifícios, o campus inicialmente proposto em 1939, fundamentava-se na ordem, caracterizada pela ortogonalidade e simetria na implantação dos edifícios, a formarem uma grande praça central. Afinal, para Mies, a tarefa da arte seria impor ordem ao caos existente (TAFURI; DAL CO, 1979, p. 312).

Contudo, segundo depoimento do próprio arquiteto (ROHE, 2006, p. 33), "o presidente Henry Heald disse que, naquele momento, [o projeto inicial] não poderia ser feito. Desse modo tive que me enfrentar com o passado; tive que desenvolver a proposta seguindo o modelo habitual de quadras, e assim o fiz. Não podia fazer nada mais". De toda forma, nos estudos posteriores, que englobaram uma área maior (em torno de 44 hectares), foi mantida a ideia de unidade definida a partir da praça central, para onde as atividades do campus se voltavam e que reforçava a autonomia do conjunto em relação ao espaço urbano [Figura 1]. Nessa praça se localizariam os dois únicos edifícios com caráter simbólico do conjunto: a biblioteca e o centro de estudantes [Figura 2]. Se a biblioteca era tradicionalmente um edifício simbólico ou ponto focal do campus norte-americano, como já proposto por Thomas Jefferson na Universidade de Virgínia (1817), a importância dada ao centro de estudantes era nova, tornada mais comum no pós-Segunda Guerra. Essa estrutura também servia para abrigar o auditório do campus, ao passo que a biblioteca abrigava ainda espaços administrativos da instituição.

O que guiava a organização geral do campus era uma malha modular, delimitadora da implantação dos edifícios e definidora de um conjunto regularmente ordenado. Essa malha com dimensões de 7,3 x 7,3m (24 x 24 pés) e altura de 3,65m (12 pés) era uma rigorosa unidade de controle, a comandar a implantação e afastamento dos edifícios, assim como o dimensionamento deles. Para Mies, a ordem era a real razão para utilização da malha modular. E a possível monotonia dessa organização era amenizada pelas variações de altura, largura e comprimento entre os edifícios, assim como pela rotação e desalinhamento de alguns deles.

Por sua vez, como lembra Banham (2003, p. 112), a "tendência à coordenação modular que perpassa o Movimento Moderno" assim como os estudos da Bauhaus em padronização dimensional foram inspirados no DIN-Format (Deustche Industrie-Normen), cada vez mais aplicado aos produtos industriais alemães no início do século XX, "sob pressão das necessidades militares e de uma situação econômica tensa". Ou seja, era um artifício de natureza fabril e com o fim de facilitar a multiplicação em série. 
Figura 1: Perspectiva do plano geral do IIT, conforme elaborado em 1940

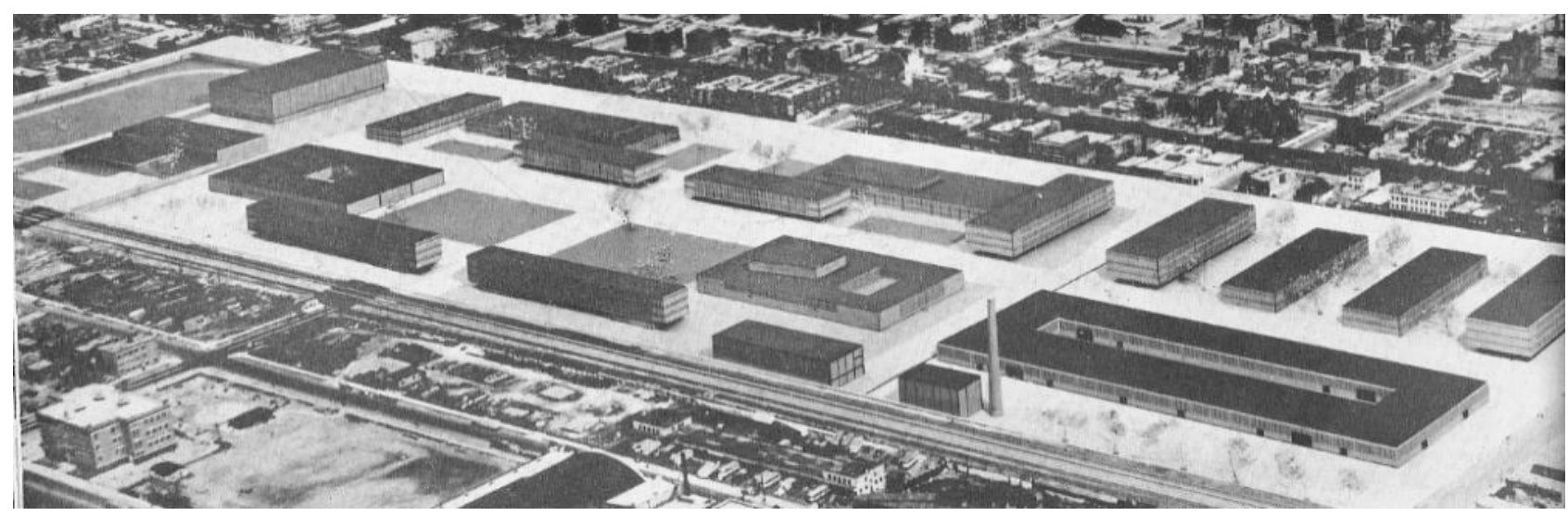

Fonte: Persitz (1958, p. 28).

Figura 2: Planta geral do IIT.

1. Área de ensaios, 2. Central de aquecimento, 3. Transformadores, 4. Pesquisas de metais e minerais, 5. Engenharia civil, 6. Física e eletricidade, 7. Manutenção, 8. Administração, 9. Equipamento mecânico, 10. Pesquisas químicas, 11. Pesquisas de engenharia, 12. Pesquisas mecânicas, 13. Biblioteca e administração, 14. Centro de estudantes, 15 e 16. Laboratórios, 17. Laboratórios de engenharia, 18. Administração de pesquisas, 19. Pesquisas físicas e elétricas, 20. Laboratórios, 21. Administração de estudos de gás, 22. Faculdade de arquitetura, 23. Engenharia mecânica, 24. Lewis Hall, 25. Faculdade de química, 26. Engenharia química e metalúrgica, 27. Alumni Memorial Hall, 28 e 29. Ginásio, 30. Estação de serviços, 31. Alojamentos, 32. Centro comercial, 33 a 41 . Grupos de alojamentos individuais em torno de uma habitação coletiva, 42. Dormitórios de meninas, 43. Hall Harr, 44 a 46. Dormitórios, 47. Fowler Hall, 48. Capela, 49. Carman Hall, 50. Gunsaulas Hall, 51. Cunningham Hall, 52. Bailey Hall, 53 a 55. Imóveis coletivos.

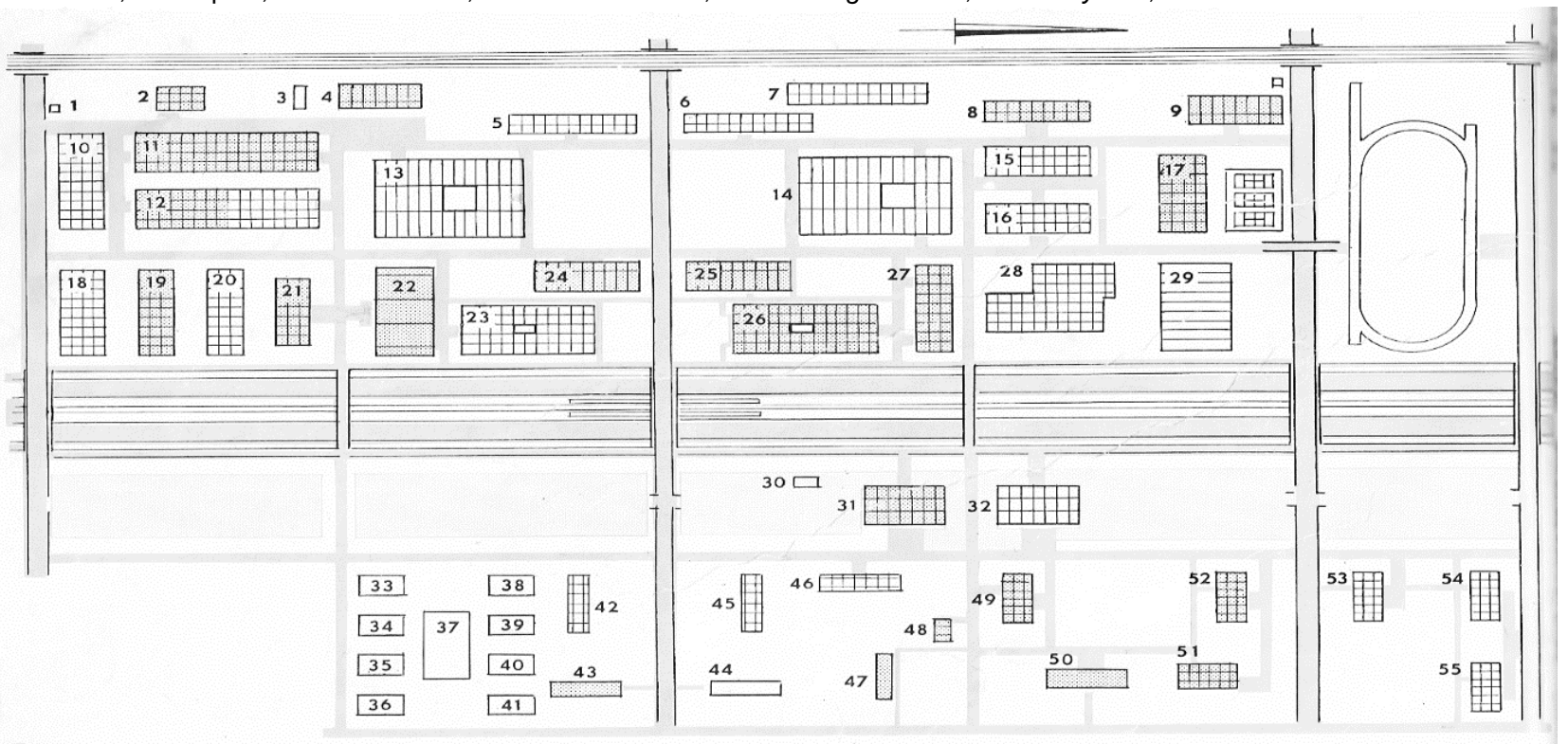

Fonte: Persitz (1958, p. 28).

Portanto, longe da liberdade de implantação de cada edifício, como almejada pelo urbanismo moderno, ao estabelecer uma norma universal que comandava a implantação e dimensionamento de todo o conjunto o plano diretor de Mies para o IIT guiava-se por um pensamento mais próprio à reprodução industrial. Não era, entretanto, uma postura clássica de estabelecer um desenho fixo, apesar da busca por uma unidade, pois a malha modular dava a oportunidade de conciliar os acréscimos ou as modificações posteriores, sem afetar a unidade inicial. Em cada interseção da malha era possível inserir pilares e, por sua vez, "conectar cada edifício em qualquer ponto e conservar ao mesmo tempo o sistema ortogonal” (ROHE, 2006, p. 21). A malha só não deveria ser reproduzida em dois edifícios: a biblioteca e a administração, que, pelo seu caráter monumental em relação ao conjunto, seguiriam um módulo mais amplo, $19,5 \times 19,5 \mathrm{~m}$, e teriam altura de $9,0 \mathrm{~m}$. Com efeito, mesmo os edifícios posteriores e projetados por outros arquitetos, como Holabird \& Root e S.O.M., obedeceram a essa modulação, numa confirmação da força dessa "unidade puramente ideal", como apontam Tafuri e Dal Co (1979, p. 310). 
Nesse sentido, apesar das especificidades do local e da organização simétrica e axial do conjunto, Mies estabeleceu, em meio a uma "tábula rasa", uma solução universal que possibilitava o ordenamento de todo o campus e uma referência para futuras ocupações ou modificações. A malha tanto poderia ser reproduzida em novas ampliações do campus quanto novos edifícios poderiam ser reproduzidos conforme a malha existente. Essa ordem racional propiciada pela malha modular valorizava a possibilidade de reprodução e flexibilidade do conjunto em lugar de soluções particulares ou específicas. "Además, un proyecto tan grande y que se extendería a lo largo de varios años requería que algunas partes pudieran ser terminadas por otros diseñadores" (SCHULZE, 1986, p. 229). Nessa direção, Mies esboçava uma nova abordagem ao plano diretor, baseada nas ideias de crescimento e mudança da instituição ao longo do tempo, como se tornaria comum no pós-Segunda Guerra, ao contrário da anterior concepção do plano como uma solução formal fixa e preestabelecida.

Com a malha modular determinada, toda a atenção de Mies concentrou-se na definição dos edifícios, projetados por ele mesmo e que seguiam o princípio de guardar na identificação de suas formas o esquema da malha modular (TAFURI; DAL CO, 1979, p. 310). Em lugar de buscar uma forma específica conforme o uso de cada edifício do IIT, Mies mais uma vez preferiu, dentro da ideia de padronização, a busca por uma solução universal ou uma forma-tipo, que pudesse atender a diversos usos ou pudesse ser reproduzida para distintas funções. Nesse momento, as ideias de flexibilidade e reprodutibilidade assumiram máxima importância no projeto do IIT, pois, diante da quantidade de edifícios a serem construídos no campus e da diversidade de usos, o extenso e complexo encargo de projetá-los poderia ser facilitado pelo recurso da padronização.

Segundo o próprio Mies (2006, p. 33), "tínhamos que construir edifícios universitários e frequentemente não sabíamos para que seriam utilizados; assim que tivemos que encontrar um sistema que possibilitasse a utilização dos edifícios como salas de aula, oficinas ou laboratórios".

Essa preocupação, embora corriqueira nesta fase de sua obra, assume no projeto do IIT uma importância fundamental. Pois, diante das constantes mudanças de usos e das novas necessidades ou equipamentos nos edifícios universitários, a flexibilidade era um requerimento importante. Um edifício de laboratório tanto podia assumir uma nova distribuição interna, em função da inserção de novos equipamentos de pesquisa, quanto podia ser requerido para outros fins acadêmicos, como salas de aulas teóricas, em função das contingências da instituição. Como percebido pelo próprio Mies:

Je luis disais: pour l'armour du ciel, pourquoi ne conçois-tu pas le bâtiment assez grand pour pouvoir y marcher librement et pas seulement dans une direction prédéterminée? Nous ne savons pas si les gens l'utiliseront comme nous l'avons souhaité. D'abord, les fonctions ne sont pas claires; ensuite, elles ne sont pas constantes - elles changent plus vite que le bâtiment. Nos bâtiments durent pendant des siècles. Les ascenseurs, le chauffage, etc, s'usent, mais la structure, elle, ne s'use pas (ROHE apud COHEN, 1994, p. 98).

Com efeito, conforme demonstram os estudos de 1939 de Mies para os edifícios do IIT, a modulação escolhida podia atender diferentes atividades didáticas. Três dimensões de salas, com 1, 1,5 ou 2 módulos de comprimento, poderiam abrigar laboratórios, aulas teóricas ou aulas de desenho. Para isso foi importante também a definição de um amplo espaço livre interno, cujo tema foi progressivamente desenvolvido pelo arquiteto. Pois, como defendia Mies, não fazia mais sentido afirmar que a forma deveria seguir a função:

Assim que um tipo, como o centro de convenções ou o museu, pode ser utilizado para outros fins... Já não se trata de "a forma segue - ou deveria seguir - à função". De qualquer maneira, tenho certas dúvidas sobre estas afirmações. Havia alguma razão quando se afirmou, mas não é possível fazer uma lei a partir daí... Um edifício de habitações poderia ser feito sem problemas a partir de um de escritórios (ROHE, 2006, p. 73).

O Crown Hall (1950-56), uma de suas últimas obras no IIT, levou à última instância essa preocupação, ao trazer toda a estrutura de suporte para o exterior do edifício e transformar seu interior numa imensa área livre desprovida de pilares. Isso se deu graças às quatro vigas em treliças de aço que sustentavam a coberta do edifício a partir de seu exterior.

Jugé par Colin Rowe 'trop pur pour être utile', Crown Hall est la première formulation complèment réalisée de ce grand espace où tout est possible, que Mies opposait dèjá les anées 1920 aux stratégies d'adaptation fonctionelle de Häring (COHEN, 1994, p. 98). 
Dentro dessa flexibilidade espacial, os edifícios do IIT assumiram um caráter de pavilhão, comparado, em geral, à arquitetura fabril alemã, da qual emergiram manifestações iniciais da arquitetura moderna e com a qual Mies tivera contato próximo. De 1908 a 1911, ele acompanhou, durante seu estágio com Peter Behrns (1886-1940), o projeto da Fábrica de Turbinas da AEG (1908-1909), em aço e vidro. De 1926 a 1932, foi vicepresidente da Deutscher Werkbund. E, mais tardiamente, Mies projetou a Fábrica Verseidag (1930-35), em Krefeld (Alemanha), considerada um dos precedentes do IIT.

Certamente a simplicidade formal, em especial dos primeiros edifícios propostos por Mies para o IIT, como o Alumni Memorial Hall (1945-46), dedicado à memória dos alunos mortos na Segunda Guerra Mundial, motivaram a comparação à arquitetura fabril [Figura 3]. Esse edifício, em particular, assumiu o caráter de protótipo aos posteriores, uma vez que suas exigências funcionais e dimensões se assemelhavam a diversos outros previstos no plano geral de Mies. O edifício possuía dimensão de 21,9 x 65,7m (3 x 9 módulos), cujo espaço interno era estruturado pela disposição regular de pilares, conforme a malha modular do campus.

Essa mesma dimensão de bloco deu origem a outros edifícios, embora com disposições internas diferentes, como a Faculdade de Química ou Wishnick Hall (1945-46). Ambos mantinham semelhantes disposições das circulações verticais e dos acessos, os quais, distribuídos em fachadas opostas, permitiam a permeabilidade do edifício, não obstante a ausência de pilotis. Porém o Alumni Memorial Hall possuía um saguão central $(14,6 \times 36,5 \mathrm{~m})$ com pé direito duplo e sem pilares intermediários e o Wishnick Hall possuía, nessa mesma porção do edifício, um auditório, com o mesmo recurso de eliminar parte da estrutura portante. Outros blocos com igual dimensão poderiam ser reproduzidos a partir dessa solução-tipo, já que a flexibilidade interna alcançada dispensava a necessidade de grandes variações entre os edifícios, como já exaltado em 1942 na Architectural Forum (BUILDINGS..., 1942, p.14).

Figura 3: Abaixo, planta baixa do Alumni Memorial Hall (1945-46), e, mais abaixo, Faculdade de Química ou Wishnick Hall (1945-46).

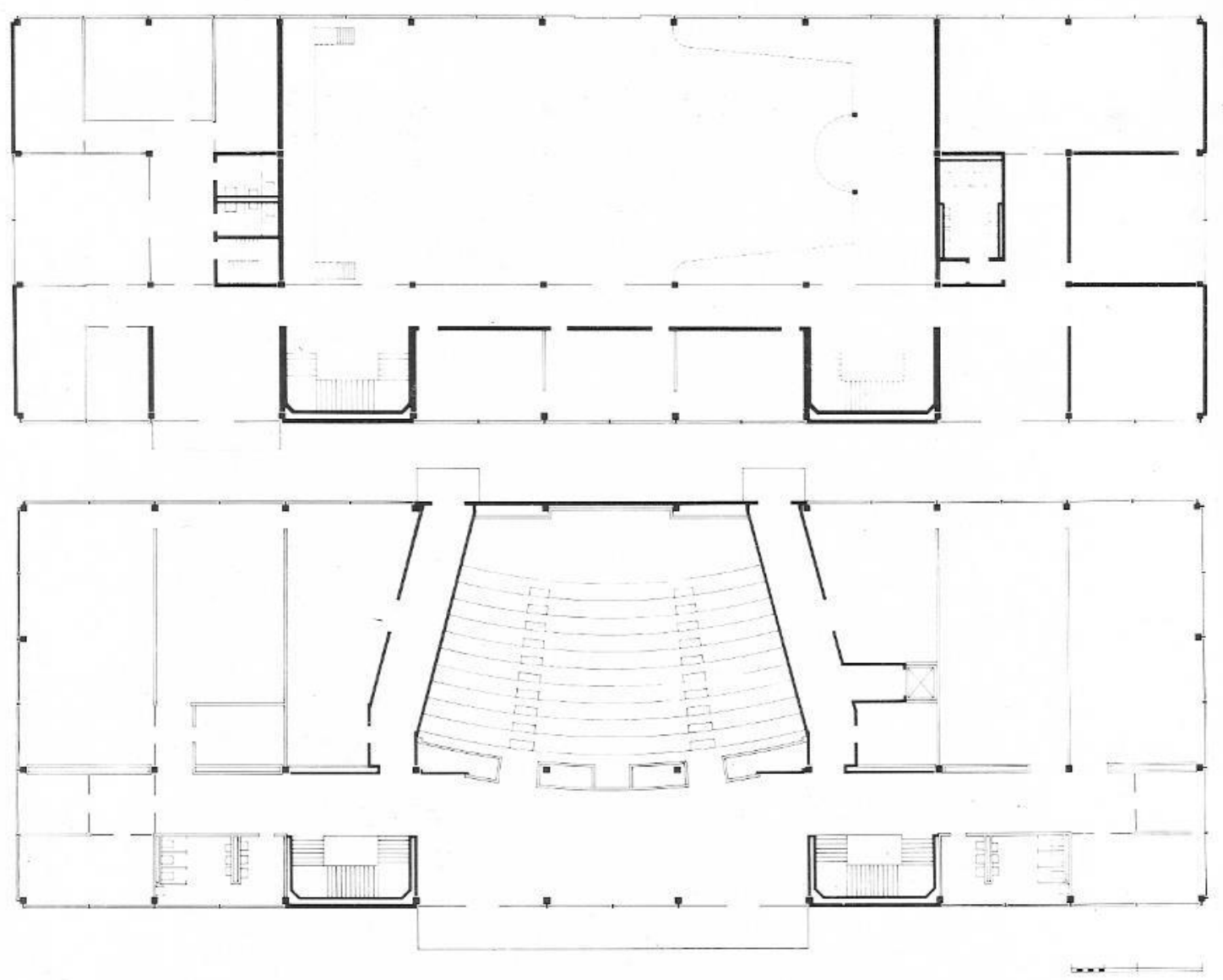

Fonte: Spaeth (1985, p. 142).

O material escolhido para a estrutura foi o aço, industrializado e abundante nos EUA, não obstante as momentâneas dificuldades em sua obtenção durante a Segunda Guerra Mundial. Como Mies parecia deduzir, 
nos Estados Unidos seria possível criar com esse material uma retícula com colunas e vigas distribuídas regularmente e preenchê-la com diferentes materiais, em especial tijolos e vidro, que the pareciam ser os complementos mais econômicos e naturais do aço, ao se ajustarem facilmente aos espaços disponíveis (BLAKE, 1963, pp. 193-4). Assim a forma do edifício passaria a ser uma consequência da própria estrutura, em lugar de ser o objetivo principal do arquiteto.

Porém, diante da necessidade de recobrir o aço com concreto nas construções com dois ou mais pavimentos, para protegê-lo contra incêndio, não foi possível utilizar uma solução padronizada de estrutura. Dos 21 edifícios de Mies construídos no IIT: 06 foram realizados em aço aparente, em geral com único pavimento; 06 foram realizados em aço protegido por concreto; 06 foram realizados em concreto armado, como os três edifícios de alojamentos (Carman Hall, Bailey Hall e Cunninghan Hall), e 03 foram realizados em alvenaria estrutural, como a capela (HERMIDA, 2011, pp. 270-2). De toda forma, independentemente da diferença de materiais ou acabamentos utilizados, foi preservada a mesma modulação estrutural que guiava o ordenamento de todo o campus.

O tratamento universal das fachadas dos edifícios reforçava a unidade do conjunto, em contraponto à diversidade de usos e de estruturas. Com efeito, entre o edifício de Pesquisas de Metais e Minerais (194243), a primeira construção realizada por Mies no campus do IIT, e o Crown Hall (1950-56), destinado a Faculdade de Arquitetura e Urbanismo e sua última obra na instituição, a linguagem formal manteve poucas variações. Mesmo a Central de Aquecimento (1949-1950) e a Capela (1952) eram distinguidas apenas por seus volumes e tratamentos específicos.

Uma retícula de aço entreposta por painéis de vidro e alvenarias de tijolos aparentes dava identidade às construções do IIT [Figura 4]. Não havia mais o sistema independente entre fechamento e estrutura, que caracterizou a produção anterior de Mies na Alemanha, mas um sistema unitário em que os fechamentos eram coordenados pela modulação estrutural do edifício. O papel marcante da estrutura derivava provavelmente, como apontado por Cohen (1994, pp. 8-9), da influência de "[...] Viollet-le-Duc et son précepte selon lequel "toute forme qui n'est pas ordonnée par la structure doit être repoussée".

Figura 4: Vista da fachada norte do Alumni Memorial Hall.

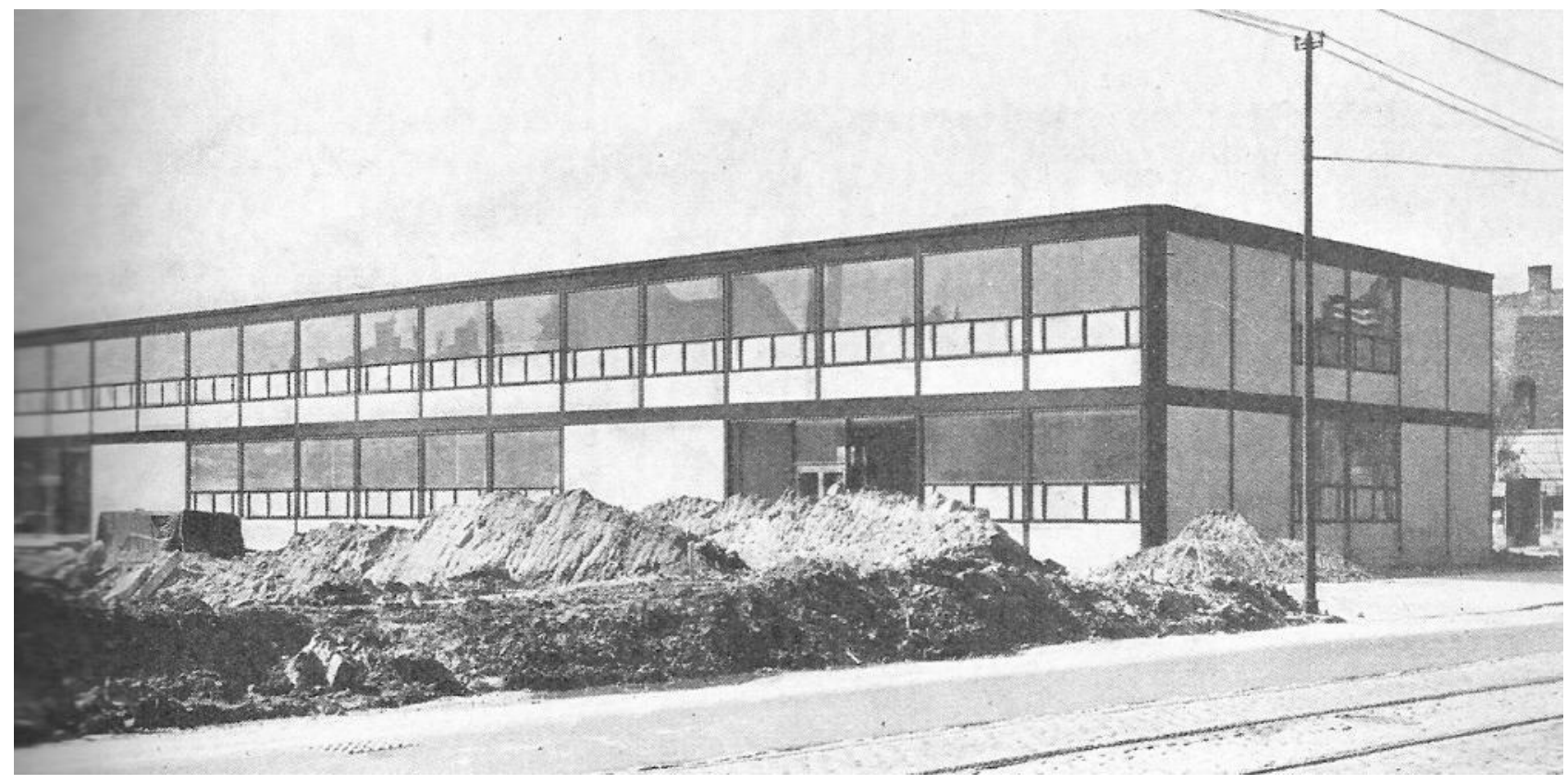

Fonte: Johnson (1960, p. 149).

Por sua vez, o uso do tradicional tijolo remetia tanto aos edifícios preexistentes da instituição quanto retomava a afinidade anterior de Mies com uso desse material em sua atuação na Alemanha. E, em lugar de recobri-lo com uma superfície lisa, como fazia a maioria dos arquitetos que the foram contemporâneos, a fim de conseguir com materiais tradicionais uma aparência mais avançada e própria à "Arte Maquinista" (BLAKE, 1963, pp. 158-9), preferiu uma atitude purista em relação à construção, deixando os tijolos aparentes.

As retículas reproduziam nas fachadas a mesma modulação utilizada no plano geral $(7,3 \times 7,3 \times 3,65 \mathrm{~m})$, a reforçar a unidade do conjunto, seja dos edifícios em relação ao plano geral, seja deles entre si [Figura 5]. 
Mais do que isso, as retículas podiam ser reproduzidas em distintas situações: diferentes quantidades de pavimentos, diferentes dimensões de edifícios ou diferentes disposições de aberturas e fechamentos. E, como suas subdivisões eram autônomas, poderiam receber o tipo de acabamento (esquadrias de vidro ou tijolos aparentes) apropriado a cada situação. No Alumni Memorial Hall, assim como na maioria dos edifícios, a retícula era sobreposta à estrutura portante de aço encoberta por concreto. Com isso, ressaltava-se a leveza da estrutura metálica, já que a proporção da estrutura primária tivera sido modificada pela proteção contra incêndio. Mesmo assim esse elemento não tocava o solo, para não simular uma função estrutural que não detinha.

A arquitetura dos edifícios do IIT seguia formas-tipo baseadas na flexibilidade de uso interno e na possibilidade de serem reproduzidas, e explorava um caráter universal, revelado tanto em sua solução espacial quanto em sua solução plástica.

Se a simplicidade formal dos edifícios do IIT sinalizava sua possibilidade de reprodução, acentuada ainda pela malha modular estendida por todo o campus, os detalhes construtivos se aproximavam de semelhante orientação, ao buscar a economia de meios, aliada ao refinamento plástico. Tal postura guardava alguma aproximação à filosofia da Deutscher Werkbund, à qual Mies esteve vinculado, ao resgatar o objetivo dessa associação alemã em unir a reprodutibilidade do produto industrial à qualidade artística.

Figura 5: Conjunto de edifícios em torno do Alumni Memorial Hall (ao fundo).

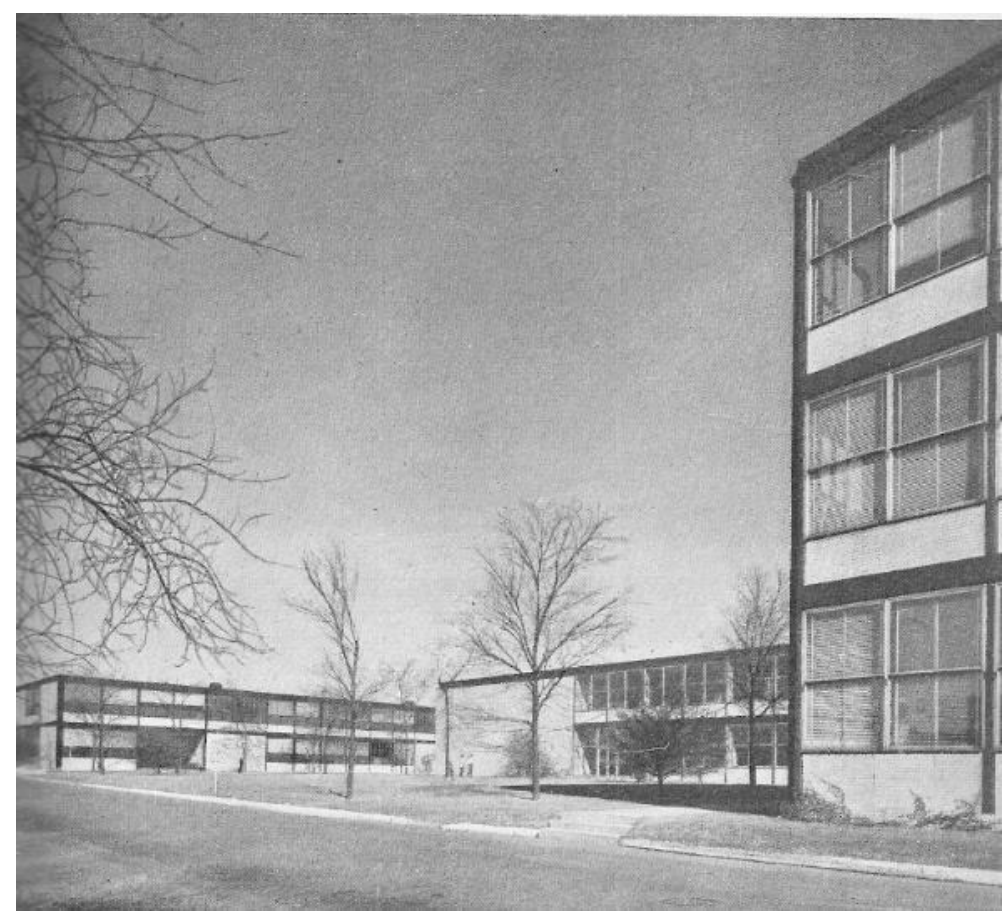

Fonte: Johnson (1960, p. 135).

O refinamento dos detalhes construtivos vinha qualificar a solução quase esquemática das formas-tipo utilizadas no IIT e associadas à arquitetura fabril. Uma simples esquina do edifício elevava-se a um exaustivo e minucioso estudo sobre as possibilidades de exploração plástica de junção entre os diferentes materiais e técnicas construtivas, além de não estar desprovida do desejo de provocar alguma reação poética no observador [Figuras 6 e 7]. Mies chegava a fazer maquetes em tamanho natural de partes do edifício para avaliar suas proporções, dentro de um processo contínuo de destilação de ideias até chegar a sua máxima pureza (BLAKE, 1963, pp. 149, 192). Uma preocupação constante em sua obra era a ordem, fosse essa estrutural ou monumental (COHEN, 1994, p. 8).

Diante da variação de tipos de estruturas no IIT (aço aparente ou revestido, concreto armado e alvenaria estrutural), também variavam as soluções dos detalhes, para se adequarem a cada situação específica. Porém mantinha-se a padronização dos componentes, por meio de uma linguagem formal comum e pelo uso de um conjunto semelhante de materiais. 
Era a valorização da técnica como qualidade artística que se privilegiava neste momento. Para Frampton (1997, p. 282), esta última fase da obra de Mies, da qual faz parte o IIT, é caracterizada por uma "monumentalidade intrínseca" baseada no refinamento e nas "qualidades expressivas de uma técnica objetiva de construção, concebida com lógica e executada com rigor" e a qual era historicamente determinada. A tecnologia era para ele a manifestação cultural do homem moderno (FRAMPTON, 1997, p. 282), de modo que a arquitetura deveria ser fruto desse tempo. Consequentemente essa passava a ser também monumentalizada em sua obra.

Figuras 6 e 7: Detalhes da fachada do Alumni Memorial Hall.
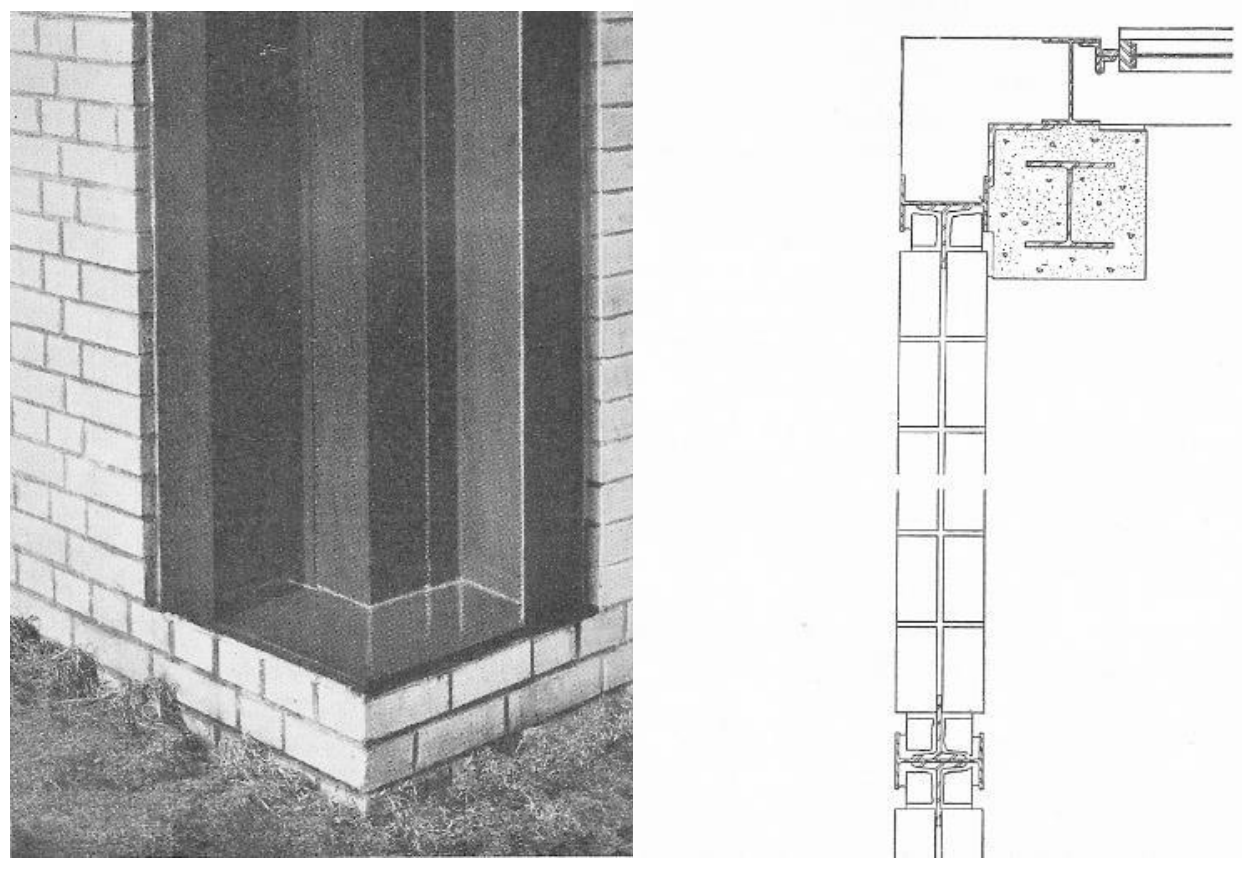

Fonte: Johnson (1960, p. 150-151).

$\mathrm{Na}$ escala do detalhe, o IIT assumia um lado mais individualizado, cuja autenticidade era mais dependente da criatividade ou genialidade do artista. "El detalle, en la medida que condensa el sistema constructivo entero, es un requisito fundamental de la forma: el momento intenso de relación - constructiva y visual - de los materiales" (HERMIDA, 2011, p. 16). Por conseguinte, sua reprodução por outros autores tornava-se mais limitada.

Consequentemente, tais soluções procuravam conciliar uma adequada solução construtiva a um resultado visual agradável. Os perfis de aço acrescidos à retícula da fachada tanto serviam para permitir uma correta fixação do tijolo ao aço quanto serviam para ressaltar a distinção entre os elementos construtivos diferentes. Dentro dessa ótica, não fazia sentido dissimular o uso dos materiais ou técnicas construtivas ou não se valer das potencialidades dos produtos industriais, em especial a esbelteza das estruturas de aço e os grandes painéis de vidro, os quais chegaram a ser os maiores então construídos. Era, pois, na escala mais reduzida do IIT, a dos detalhes construtivos, onde se revelava o lado mais refinado e individualizado do projeto de Mies, voltado a uma monumentalização da técnica. Sua economia de meios e racionalismo construtivo, como a padronização dos componentes, não o distanciava de uma hipótese de seriação, embora adaptada à variedade de situações construtivas a serem atendidas. Com efeito, a retícula de aço do Alumni Memorial Hall se assemelhava à utilizada por Mies nas fachadas do edifício de apartamentos Lake Shore Drive (1951), em Chicago.

Enfim, o projeto de Mies para o IIT deve ser entendido além da organização simétrica e axial de seu conjunto. Pois, num momento em que o campus passava por reavaliações, o IIT punha em evidência, mesmo que de forma particular, o planejamento centrado no crescimento e na mudança. E antecipava essa questão que se tornaria central nos anos posteriores, marcados pela necessidade de rápida expansão do ensino superior, afora a ampliação da complexidade de sua estrutura, quando a busca por uma forma final fixa daria lugar à flexibilidade no processo de planejamento. 
Para Mies, no entanto, o crescimento e a mudança eram condicionados por uma rigorosa padronização formal, que se estendia da escala mais reduzida dos componentes construtivos, passava pela solução espacial dos edifícios, até atingir a organização física do conjunto. Com isso explorava a possibilidade de reprodução que se tornava ampliada com os novos meios de reprodução técnica e com o processo de seriação próprio ao universo industrial. Embora já houvesse uma aproximação anterior de Mies ao universo industrial, quando de sua atividade na Alemanha, o que mudava em sua atuação no IIT era a intensidade com que isso ocorria, diante da grande disponibilidade de produtos industriais nos Estados Unidos, como o aço, e do apoio por ele aí recebido.

Diante da rigidez na estruturação do conjunto, era na arquitetura dos edifícios e na solução de seus componentes construtivos que ficava mais clara a contribuição do IIT. Os espaços flexíveis dos edifícios, com possibilidade de atenderem a distintos usos, se tornariam um tema recorrente ao ensino superior, especialmente com a distinção das construções por seus usos (pesquisa, aula, administração) e não mais por campos de conhecimento (Engenharia, Direito, Medicina).

Por outro lado, como comum à diversidade do sistema de ensino superior dos Estados Unidos, o IIT era também uma solução particular, fruto da orientação individual da instituição e de seu próprio arquiteto. Sua arquitetura cumpria também o valor simbólico de representar a identidade tecnológica da instituição. Henry Heald, presidente do IIT, "défendra Mies face aux résistances du corps enseignant" e rejeitou inclusive uma doação que implicaria na construção de um edifício gótico, além dessa instituição ser dominada por centros de pesquisas financiados pela indústria e pelos militares (COHEN, 1994, p. 87).

\section{CONSIDERAÇÕES FINAIS}

Tanto o estudo de Cooke quanto o projeto de Mies para o IIT colocavam em tensão o ideário tradicional de campus norte-americano, ao priorizarem a racionalização do espaço físico universitário. Para Cooke, essa modernização se baseava na ampliação da eficiência do uso de ambientes e edifícios, a exemplo do compartilhamento desses por diferentes departamentos. Para Mies, essa modernização era guiada por um planejamento flexível baseado no princípio da seriação, no qual a utilização de uma malha modular guiava a organização do campus, dos edifícios e de seus componentes construtivos.

Tais ideias eram gestadas num momento de amplo investimento privado dirigido à modernização do ensino superior no país, diante da insatisfação com as instituições existentes. Dessa forma, esses dois eventos, mesmo que analisados individualmente, eram parte de um processo mais amplo e não restrito ao debate arquitetônico e urbanístico. As transformações no espaço físico da universidade estavam relacionadas a demandas externas provenientes do anseio de maior eficiência na gestão do ensino superior. E, apesar da diversidade do sistema de ensino superior norte-americano, fundado na autonomia entre os estados, os investimentos e as ações das grandes fundações privadas, como a Carnegie Foundation, incitavam a possibilidade de uma unitária difusão de ideias em escala nacional.

Certas discussões que posteriormente se tornariam corriqueiras no direcionamento da reforma universitária no Brasil, como quantificar o tempo de utilização dos edifícios e defender a opção por construções pavilhonares, já eram nos Estados Unidos postas em evidência em início do século XX, de modo que a circulação dessas ideias no Brasil pode ter ocorrido já nessa época.

\section{REFERÊNCIAS}

BANHAM, R. Teoria e projeto na primeira era da máquina. 3 ed. Traduzido por A. M. Goldberger Coelho (Tradução de Theory and Design in the First Machine Age). São Paulo: Perspectiva, 2003.

BLAKE, P. Maestros de la arquitectura: Le Corbusier, Mies van der Rohe, Frank Lloyd Wright. Traduzido por Ludovico C. Koppmann (Tradução de "The master builders"). Buenos Aires: Victor, Leru, 1963.

BARROW, C. W. Corporate Liberalism, Finance Hegemony, and Central State Intervention in the Reconstruction of American Higher Education. Studies in American Political Development, 6. 420-443. Cambridge: Cambridge University Press, 1992.

BUILDINGS TO COME. The Architectural Forum, Boston, Feb. 1942, p.14.

COHEN, J. L. Mies van der Rohe. Paris: Hazan, 1994.

FRAMPTON, K. História crítica da arquitetura moderna. Traduzido por Jefferson Luiz Camargo (Tradução de Modern Architecture - A critical view). São Paulo: Martins Fontes, 1997. 
HERMIDA, M. A. El detalle como intensificación de la forma: El Illinois Institute of Technology de Mies van der Rohe. 2011. Tese (Doutorado no Departamento de Projetos Arquitetônicos) - Universidad Politécnica de Catalunya, Barcelona. Disponível em http://www.tdx.cat/handle/10803/96156. Acesso em 12 jun. 2014.

JOHNSON, P. C. Mies van der Rohe. Traduzido por Nicoletta Ottolenghi (Tradução de: "Mies van der Rohe"). Buenos Aires: Victor Leru S. R. L., 1960.

ROHE, M. V. D. Conversas com Mies van der Rohe: certezas americanas. Entrevistador: Moisés Puente. Traduzido por Maria Luiza Tristão de Araújo. Barcelona: Gustavo Gili, 2006.

PEREIRA, F. T. B. Exporting progress: os norte-americanos e o planejamento do campus no Brasil. 2017. Tese de Doutorado, Instituto de Arquitetura e Urbanismo, Universidade de São Paulo, São Carlos. Disponível em http://www.teses.usp.br/teses/disponiveis/102/102132/ tde-04092017-105123/. Acesso em 07 nov. 2017.

PERSITZ, A. L'oeuvre de Mies van der Rohe. Boulogne/Seine: L'Architecture d'aujourd'hui, 1958.

SCHULZE, F. Mies van der Rohe: una biografía crítica. Traduzido por Jorge Sainz Avia (Tradução de "Mies van der Rohe: a critical biography" - Maestros de la arquitectura). Madrid: Blume, 1986.

SPAETH, D. Mies van der Rohe. Traduzido por Santiago Castán. Barcelona: Gustavo Gili, 1985.

TAFURI, M.; DAL CO, F. Modern Architecture/2: history of world architecture. Traduzido por Robert Erich Wolf (Tradução de "Architettura contemporanea"). New York: Electa/Rizzoli, 1979.

TURNER, P. V. Campus: an American planning tradition. Cambridge: MIT Press, 1984.

NOTA DO EDITOR (*) O conteúdo do artigo e as imagens nele publicadas são de responsabilidade do(s) autor(es). 